\title{
An efficiency analysis of grant awarded research projects: a case study of a Malaysian public university
}

\section{Noor Saifurina Nana Khurizan and Adli Mustafa*}

School of Mathematical Sciences, Universiti Sains Malaysia, 11800 Pulau Pinang, Malaysia

Email: noorsaifurina_nk@yahoo.com

Email: adli.mustafa@usm.my

*Corresponding author

\section{Hamidah Abd. Hamid}

School of Communication, Universiti Sains Malaysia, 11800 Pulau Pinang, Malaysia

Email: hamidah@usm.my

\begin{abstract}
This paper presents a novel way of evaluating the performance of grant awarded research projects using two multi-criteria decision-making methods, the measuring attractiveness through a category-based evaluation technique (MACBETH) and data envelopment analysis (DEA). This study examines the relative efficiency of the research projects as a whole and according to four groups of research disciplines. A case study of sponsored research projects from the Universiti Sains Malaysia, Penang, Malaysia was presented in this paper. The MACBETH methodology was employed before conducting the DEA analysis to group the output variables and therefore increasing the discrimination power of DEA. A total of two inputs and four outputs, after the MACBETH analysis, were used in the DEA analysis. Also, a non-parametric statistical test, the Kruskal-Wallis test, was employed to compare the performance of the research projects according to research discipline, years sponsored and a number of collaborations. Finally, a potential improvement of selected input and output was discussed as a result of a further investigation of the DEA analysis.
\end{abstract}

Keywords: measuring attractiveness through a category-based evaluation technique; MACBETH; data envelopment analysis; DEA; sponsored research; R\&D efficiency; performance measurement; university decision making.

Reference to this paper should be made as follows: Khurizan, N.S.N., Mustafa, A. and Hamid, H.A. (2018) 'An efficiency analysis of grant awarded research projects: a case study of a Malaysian public university', Int. J. Public Sector Performance Management, Vol. 4, No. 1, pp.80-97. 
Biographical notes: Noor Saifurina Nana Khurizan is a $\mathrm{PhD}$ candidate at the School of Mathematical Sciences, Universiti Sains Malaysia. Her research interests are in the theory and application of multiple criteria decision making techniques and data envelopment analysis.

Adli Mustafa is a Senior Lecturer at the School of Mathematical Sciences, Universiti Sains Malaysia. His teaching and research interest is in operations research, particularly, on the topics of multiple criteria decision making, data envelopment analysis, scheduling, simulation and queueing theory. He has authored articles published in Computers \& Operations Research, OMEGA, Computers \& Industrial Engineering, Expert Systems with Applications, Knowledge-Based Systems, Applied Mathematical Modelling, Group Decision and Negotiation, Discrete Event Dynamic Systems, among others. He holds a $\mathrm{PhD}$ in Decision Sciences from The National University of Singapore.

Hamidah Abd. Hamid is a Senior Lecturer at the School of Communication, Universiti Sains Malaysia. Her teaching and research interests are in journalism, communication, tourism and higher education administration. She holds an MA in Journalism from The Ohio State University, USA.

\section{Introduction}

The growing need for financial allocation to support the research and development $(R \& D)$ activities has also contributed to the rapid growth of research evaluation study. $R \& D$ are mainly divided into two areas namely industrial $R \& D$ and educational $R \& D$. While both areas focus their R\&D on their competitive environment, the industrial R\&D is usually dedicated to the firms' production and sales whereas the educational R\&D is dedicated more towards improving the current research and therefore enhancing its overall strength. Research evaluation and performance measurement are needed to identify efficient R\&D that has succeeded in achieving its target.

Over the years, various methodologies have been developed and applied to assess the performance of R\&D activities. This, among others, is due to the competitive environment in gaining financial support either from the government or private sector. In industrial R\&D, Zhang et al. (2003) discussed the stochastic frontier estimation of the R\&D production function of Chinese firms. Chen et al. (2004) and $\mathrm{Li}$ and $\mathrm{Hu}$ (2014) applied the methodology of Data Envelopment Analysis (DEA) and super-efficiency DEA, respectively, in high-tech industry R\&D evaluation. Lee and Yoon (2015) applied two estimation methods, DEA and regression analysis, in an efficiency analysis of R\&D activities of small- and medium-sized enterprises (SMEs) in Korea. In educational R\&D, various methodologies have been applied. For example, Korhonen et al. (2001) used DEA to compliment the decision maker's preferences of an efficient frontier in a value analysis of academic research. Feng and Lu (2004) used analytic hierarchy process (AHP) and DEA to evaluate the growth of R\&D management. The sole usage of DEA can be found in the work of Sharma and Thomas (2008) in evaluating the inter-country $\mathrm{R} \& \mathrm{D}$, the work of Abramo et al. (2011) in evaluating research in universities, the work of 
Hao and Yanhui (2014) on R\&D development and the work of Afzal and Lawrey (2014) on the efficient use of R\&D expenditure. Besides that, DEA-malmquist index has been employed in assessing the performance of research in an academic department (Agasisti et al., 2011) and finally, cluster analysis methodology in examining the performance of university research (Ibanez et al., 2013).

From the literature, DEA seems to be the most popular methodology for evaluating the performance of R\&D activities. Thus the researchers have decided to employ the same methodology in various analyses conducted in this particular study. However, this research differs from the previous studies as it integratively used MACBETH with the DEA. The purpose of doing so was to overcome some of the issues related to the large number of output measures in DEA (Meng et al., 2008). Among them is the lower discrimination power of DEA.

The purpose of this study was to evaluate the performance of sponsored research projects which is part of the educational R\&D, overall and by discipline. From there, we conducted statistical analysis to examine the effect of environmental variables on the efficiency score. For further analysis, we investigated the possible improvement for selected input and output variable. This study takes an example of educational R\&D with a case study involving 152 sponsored research projects.

Malaysia is a nation state in the South East Asian region with a geographical area of over 330,000 square kilometres and a 2016 population of over 31.7 million (http://www.dosm.gov.my). To date, Malaysia has progressed into the eleventh national economic development plan since its independence in 1959. A few classic works (Dana, 2007, 1987; Rahimah, 1996) have discussed these economic development plans. R\&D have always been a significant factor in these plans. One area that received a major focus was the public universities' R\&D. Malaysia has 20 public universities, out of which five were given the research university status. With the award of such status, came additional funding in the form of research grants and commercialisation of research. With more universities competing for research status and grant money, it is important that the process of awarding grants be as efficient as possible. Appropriate decision-making tools should be used to ensure transparency in the evaluation of its effectiveness.

Currently, many multi-criteria decision-making tools have been developed and utilised to help policy makers. Each has its shortcomings; thus an integrated model utilising more than one method may help to address the constraints of a one-method model.

This paper describes such attempt by outlining the data and variable selection before discussing the application of MACBETH and DEA. MACBETH involves subjective data commonly used in the arts whereas DEA involves objective data commonly used in the Sciences.

\section{Data and variables selection}

This study dealt with the 8th Malaysian Plan Intensification of Research in Priority Areas (IRPA) grant receivers in Universiti Sains Malaysia. A total of 152 research projects were selected to receive the funding from the year 2001 onwards. All of these research projects were classified into the discipline relevant to their respective research areas. All the research projects in this study were completed within 12 months to 64 months. The 
disciplines were divided into four categories, namely medicines, sciences, engineering and others (consists of social sciences and environmental studies). The number of research projects in each discipline is indicated in Table 1.

Table 1 Summary of discipline classification

\begin{tabular}{lc}
\hline Discipline & Total number of research projects \\
\hline Medicines & 34 \\
Sciences & 58 \\
Engineering & 48 \\
Others & 12 \\
\hline
\end{tabular}

To carry out the DEA analysis, the variables for the input and output needed to be determined beforehand. The variables chosen for this analysis were fully utilised from the available data set. A total of 21 data sets were collected and three of them were classified as the input data; the number of researchers, the amount of grants and the duration taken to complete the awarded research. The number of researchers which acted as a labour input includes both principal researchers and co-researchers while the number of grants awarded which served as capital input (Lee et al., 2009), was the sum of money allocated to complete the research. The data set of duration was ruled out as an input since its existence would not affect the efficiency result. Such decision was made after a test of efficiency analysis was done with and without duration as an input variable. Apart from that, to support the decision made, the amount of money allocated for each research was determined in proportion to its duration (Lee et al., 2009).

Table 2 Descriptive statistics for all available data sets

\begin{tabular}{lcccc}
\hline Data sets & Mean & Standard deviation & Minimum & Maximum \\
\hline Research grants (RM) & $367,623.8$ & $1,007,138.64$ & 64,000 & $11,299,914$ \\
Researchers & 3.55 & 1.54 & 1 & 9 \\
Duration (months) & 32.3 & 7.99 & 12 & 64 \\
International journal & 2.49 & 6.3 & 0 & 68 \\
International books & 0.013 & 0.11 & 0 & 1 \\
International book chapter & 0.02 & 0.18 & 0 & 2 \\
Local journal & 0.99 & 4.54 & 0 & 54 \\
Local book chapter & 0.026 & 0.26 & 0 & 3 \\
International conference & 2.52 & 4.09 & 0 & 30 \\
Local conference & 2.89 & 4.07 & 0 & 27 \\
Other publications & 0.17 & 0.86 & 0 & 9 \\
Patent & 0.019 & 0.14 & 0 & 1 \\
Trademark & 0.026 & 0.16 & 0 & 1 \\
Copyright & 0.013 & 0.11 & 0 & 1 \\
Industrial design & 0.039 & 0.19 & 0 & 1 \\
International awards & 0.19 & 0.54 & 0 & 3 \\
Local awards & 0.16 & 0.42 & 0 & 3 \\
Postdoctoral & 0.019 & 0.18 & 0 & 2 \\
PhD & 0.58 & 0.94 & 0 & 7 \\
Masters & 1.63 & 1.84 & 0 & 12 \\
Degree & 0.4 & 1.75 & 0 & 18 \\
\hline
\end{tabular}


The remaining 18 data sets were classified as the output data with eight of them being related to publications. It was widely agreed that the most significant research output would be publications in either journal, books or even conferences. Martin (1996) stated that almost $60 \%$ of the study regarding research assessment included publications as performance analysis indicator. In this particular study, the output data under publications included international journal publications, local journal publications, international books, international book chapters, local book chapters, international conferences, local conferences and other types of publications such as magazine articles and handbooks. Four of the data sets were related to technology outputs which were the number of patents (Cullman et al., 2009; Schmidt-Ehmcke and Zloczysti, 2009), trademarks, copyrights and industrial designs. Human resources development contained four data sets; postdoctoral, $\mathrm{PhD}$ graduate, master graduate and undergraduate. The last two data sets were an award received in conjunction with the research, international award and local award which highlighted the achievement of the study. A descriptive statistics of the data sets is given in Table 2 .

Figure 1 Output classification

\begin{tabular}{|lll|}
\hline Output & Criteria & Sub-criteria \\
& Publications & \\
& International journal & International book \\
& International book chapter \\
& Local journal \\
& Local book chapter \\
& International conference \\
& Local conference \\
& Others (article, handbook, etc.) \\
& \\
& \\
& Technology output \\
& Patent \\
& Trademark \\
& Copyright \\
& Industrial design \\
& \\
& International award \\
& Local award \\
& \\
& Postdoctoral \\
& PhD \\
& Master \\
& Undergraduate \\
&
\end{tabular}

All these 18 data sets were classified into four groups to create a hierarchy to perform the first step in data transformation before moving on into the DEA analysis. Data transformation is required to improve the discrimination power of the DEA (Meng et al., 2008 ) by reducing the number of the output variables. Instead of using all 18 data sets as an individual output in the DEA analysis, the hierarchy was built to narrow down the output variables. Hence, this grouping stage was needed to perform the MACBETH methodology to get the data ready for the efficiency analysis later on. The data sets were grouped on the basis that they were comparable among themselves. The group classification is simplified in Figure 1. 


\section{MACBETH for data transformation}

\subsection{MACBETH methodology}

First developed by Bana e Costa and Vansnick (1994), measuring attractiveness through a category-based evaluation technique (MACBETH) is one of the many multi-criteria decision making (MCDM) tools aimed to assist decision makers (DM) in dealing with various decision-making processes concerning multiple criteria problems. The basic idea behind the MACBETH methodology arises from the interest in aiding DM in building an interval scale of preferences for a set of options without directly rating the options.

In the area of higher education particularly research evaluation, not many studies have been conducted using MACBETH. In 2002, Soares de Mello et al. demonstrated the application of MACBETH in assisting university calculus class evaluation process using DEA. MACBETH was used to determine the weight restriction for the DEA analysis. Bana e Costa and Oliveira (2012) applied the MACBETH methodology in faculty evaluation and showed an example of the application on faculty publications.

Upon selecting the criteria of assessment, DM was asked to make qualitative judgments for each of the criteria to find the difference of value. The MACBETH judging scale consisted of six semantic scales namely from top to bottom; extreme, very strong, strong, moderate, weak and very weak. These scales represent the difference of attractiveness of one criterion to the other within the set of criteria to be evaluated.

The MACBETH software allowed the DM to rate the options and check the consistency of the judgments at the same time. If any of the judgments are found to be non-consistent, the software would immediately ask the DM to make a correction on the related judgments by giving a suggestion straight away. Unless all of the judgments were consistent, the MACBETH software would not calculate the options score. Another advantage of using MACBETH compared to other MCDM method was that it allowed the DM to adjust the weightage of the options found according to their preferences. It gave the threshold for the weightage with lower and upper bound for flexibility in making a decision regarding the final score of the options.

Figure 2 MACBETH judgements table for publication's sub-criteria (see online version for colours)

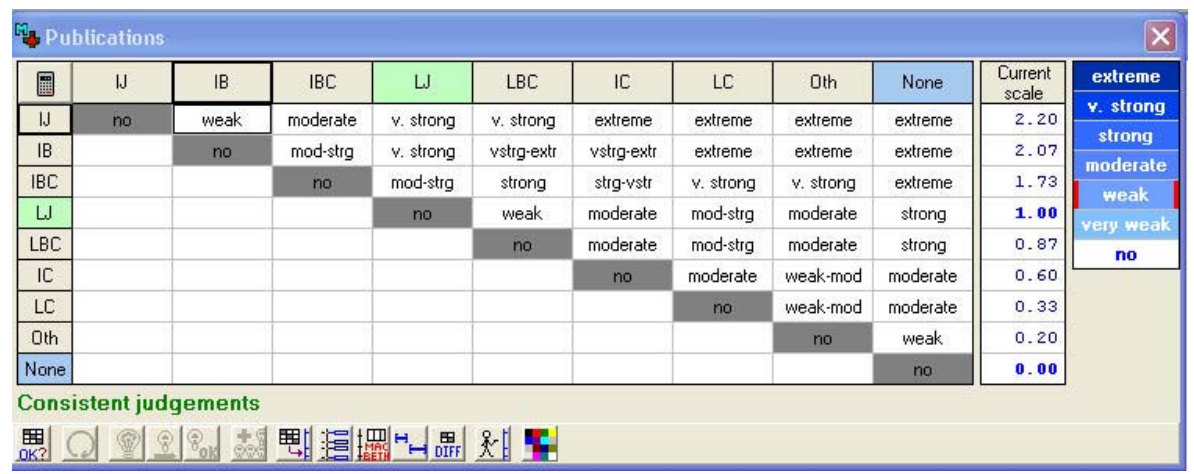

In MACBETH, DMs were first asked to arrange the sub-criteria needed to be judged. The arrangement process required the DM to organise the sub-criteria from the one he felt has 
the most important sub-criteria to the least important one. The arrangements were then used in the MACBETH software for the calculation process. In this study, the questionnaire was distributed to only one expert who represented the decision maker to examine the application of MACBETH in this context of the study. Taking the publication's sub-criteria as an example, no publications' criterion was also included in the set of options to ensure that no real sub-criteria would have a zero score (Soares de Mello et al., 2002). Figure 2 shows the publication's sub-criteria judgment in MACBETH with the current scale column representing the score for each sub-criterion. Publication in the local journal was arbitrarily chosen as references and was given the score of 1 . Table 2 summarises the MACBETH score obtained for all sub-criteria. The sub-criteria under other output criteria chosen as references were also given the value 1 .

The rest of the sub-criteria's score is presented in Table 3. The patent, international awards and $\mathrm{PhD}$ graduates are arbitrarily chosen as their respective criteria references and are assigned a value of 1 . By obtaining the score for each sub-criteria using MACBETH, the sub-criteria could be aggregated into the related single criteria thus allowing the calculation of a single score for the output criteria for the efficiency analysis.

Table 3 MACBETH judgements score for outputs' sub-criteria

\begin{tabular}{lcc}
\hline Outputs criteria & Outputs sub-criteria & MACBETH judgements score \\
\hline Publications & International journal (IJ) & 2.2 \\
& International books (IB) & 2.07 \\
& International book chapter (IBC) & 1.73 \\
& Local journal (LJ) & 1 \\
& Local book chapter (LBC) & 0.87 \\
& International conference (IC) & 0.6 \\
& Local conference (LC) & 0.33 \\
Technology output & Others (Oth) & 0.2 \\
& Patent & 1 \\
Trademark & 0.84 \\
Awards & Copyright & 0.68 \\
Human resources & Industrial design & 0.53 \\
& International awards & 1 \\
& Local awards & 0.38 \\
& Postdoctoral & 1.19 \\
& PhD & 1 \\
& Masters & 0.44 \\
\hline
\end{tabular}

\subsection{Data transformation}

In the next stage, the transformation of the data, involved two steps. The first was the calculation of the single output criteria score. Next was the standardisation process of all the input and output data. For the first step, take for instance unit R0831 publication data as an example. The aggregated score was calculated using the formula $R_{c}^{a}=\sum_{i=1}^{k} S_{c i} m_{c i}$ where $R_{c}^{a}$ represents criteria $c$ score for research $a, S_{c i}$ represents numerical data of 
sub-criteria $i$ in criteria $c, m_{c i}$ is the MACBETH score for sub-criteria $i$ in criteria $c$ and $k$ is the total number of sub-criteria for criteria $c$. We took unit R0831 publications data as an example and the data is presented, in Table 4.

Table 4 Unit R0831 publications data

\begin{tabular}{lcccccccc}
\hline Type of publications & $I J$ & $I B$ & $I B C$ & $L J$ & $L B C$ & $I C$ & $L C$ & Oth \\
\hline Number of publications & 3 & 0 & 0 & 2 & 0 & 11 & 1 & 3 \\
MACBETH score & 2.2 & 2.07 & 1.73 & 1 & 0.87 & 0.6 & 0.33 & 0.2 \\
\hline
\end{tabular}

Table 5 Descriptive statistics for inputs and outputs in whole researches

\begin{tabular}{lcccc}
\hline & Mean & Standard deviation & Minimum & Maximum \\
\hline Researchers (n) & 3.55 & 1.54 & 1 & 9 \\
Grants (RM) & $367,623.8$ & $1,007,138.64$ & 64,000 & $11,299,914$ \\
Publications (score) & 9.0471 & 19.3114 & 0 & 219.14 \\
Technology output (score) & 0.0696 & 0.2508 & 0 & 1.52 \\
Awards (score) & 0.2574 & 0.6626 & 0 & 4.14 \\
Human resource (score) & 1.3937 & 1.5692 & 0 & 10.96 \\
\hline
\end{tabular}

Table 6 Descriptive statistics for inputs and outputs in four disciplines

\begin{tabular}{lcccc}
\hline & Mean & Standard deviation & Minimum & Maximum \\
\hline Researchers (medicines) & 3.71 & 1.7843 & 1 & 7 \\
Grants (medicines) & $354,298.65$ & 341,373 & 134,000 & $1,500,000$ \\
Publications (medicines) & 9.06 & 10.4364 & 0.6 & 42 \\
Technology output (medicines) & 0.0494 & 0.237 & 0 & 1 \\
Awards (medicines) & 0.4088 & 0.8507 & 0 & 2.38 \\
Human resources (medicines) & 1.4288 & 1.5544 & 0 & 6.64 \\
Researchers (sciences) & 3.43 & 1.6234 & 1 & 8 \\
Grants (sciences) & $553,174.85$ & $1,595,832$ & 81,000 & $11,299,91$ \\
Publications (sciences) & 7.9476 & 28.5922 & 0 & 219.14 \\
Technology output (sciences) & 0.0434 & 0.237 & 0 & 1.52 \\
Awards (sciences) & 0.1255 & 0.3919 & 0 & 1.38 \\
Human resources (sciences) & 1.2129 & 1.6368 & 0 & 10.96 \\
Researchers (engineering) & 3.56 & 1.4426 & 1 & 9 \\
Grants (engineering) & $208,139.02$ & $79,632.76$ & 64,000 & 590,000 \\
Publications (engineering) & 11.6183 & 10.4898 & 0 & 40.06 \\
Technology output (engineering) & 0.1108 & 0.3027 & 0 & 1.52 \\
Awards (engineering) & 0.3658 & 0.8066 & 0 & 4.14 \\
Human resources (engineering) & 1.6665 & 1.5938 & 0 & 9.7 \\
Researchers (others) & 3.58 & 0.5149 & 3 & 4 \\
Grants (others) & $146,487.5$ & $66,329.52$ & 65,000 & 268,750 \\
Publications (others) & 4.0392 & 4.8594 & 0 & 13.12 \\
Technology output (others) & 0.0883 & 0.2063 & 0 & 0.53 \\
Awards (others) & 0.0317 & 0.1097 & 0 & 0.38 \\
Human resources (others) & 1.0767 & 1.0842 & 0 & 3.44 \\
\hline
\end{tabular}


The score for unit R0831 publications was

$$
\begin{aligned}
R_{P u b}^{R 0831} & =\sum_{i=1}^{8} S_{P u b i} m_{P u b i} \\
& =3(2.2)+0(2.07)+0(1.73)+2(1)+0 .(0.87)+11(0.6)+1(0.33)+3(0.2) \\
& =16.13
\end{aligned}
$$

Once the scores for all sub-criteria for all research units have been calculated, the second step, which is the standardisation process for all input and output data could be executed. Meng et al. (2008) stated that the reason behind the data standardisation was to remove the scale differences for all aggregated score. This process requires the application of a simple calculation using the formula $\bar{x}_{i j}=\frac{x_{i j}}{\max _{i} x_{i j}} \times 100$. Table 5 summarises all the input and output data for the 152 sponsored research projects (DMUs) whereas Table 6 shows the descriptive statistics for all main variables for all four disciplines.

\section{DEA for efficiency measurement and potential improvement}

Generally, a measure of productivity is the ratio between the output and the input. In a case where only a single input and output is considered, a frontier is said to be efficient when the line touches at least one point and all the other points are located below or above the line such that the line 'envelops' these points (Cooper et al., 2002). Such property mentioned above resulted in the naming of the methodology as DEA. The extension of the idea led to the development of DEA where multiple inputs and multiple outputs were concerned in which a weight was assigned to each input and output.

DEA was first introduced by Charnes et al. (1978) to first demonstrate the replacement of the original fractional programming of efficiency measurement into the equivalent linear programming format. This methodology often comes in handy in a problem where multiple inputs and multiple outputs are involved, with or without the existence of the production function (Adler et al., 2002; Kocher et al., 2006). On a more specific application, DEA measures the relative efficiency of the DMU in interest.

DEA efficiency analysis will rate the DMU, i.e., units under evaluation with a scoring system ranging from 0 to 100 or 0 to 1 , where 0 means the units are not efficient at all and 100 or 1 represents the highest efficiency score a DMU can obtain. Having a score of 100 or 1 means the DMU is efficient. The DMU in our case study was the grant-awarded research projects.

Two of the most basic and common DEA models are known as the CCR model and BCC model. The former was developed by Charnes et al. (1978) while the latter was developed by Banker et al. (1984) as an extension to the constant return to scale of activities in the CCR model. The BCC model has the characteristics of variable returns to scale activities.

Another aspect of this study is the objective of the analysis, which is either to minimise the input to produce the current output or to fully utilise the input to maximise the output. This research primarily employs the BCC input-oriented model to analyse the possibility of an input reduction in proportion to the output produced. On the contrary, the BCC output-oriented model was applied to study the possibility of an output improvement in proportional to the input given. Both input-oriented and output-oriented 
model could be used to analyse the efficiency of the sponsored research in this study. However, due to the interest in maximising the research output using the controllable input, the output-oriented model was more appropriate for the study of sponsored research efficiency. Hence, the input-oriented model would only be used for reference in the case of determining the possible amount of inputs with a pre-determined value of output.

Suppose the intention is to evaluate $\mathrm{DMU}_{o}$ where $o=1, \ldots, n$, with $n$ being the total number of DMU, the input-oriented BCC model as formulated by Banker et al. (1984) is

$$
\begin{array}{ll}
\min & \theta_{B} \\
\text { subject to } & \theta_{B} x_{o}-X \lambda \geq 0 \\
& Y \lambda-y_{o} \geq 0 \\
& \sum_{j=1}^{n} \lambda_{j}=1 \\
& \lambda \geq 0,
\end{array}
$$

where $\theta_{B}$ is the efficiency score of $B^{\text {th }}$ DMU, $\left(x_{o}, y_{o}\right)$ is the DMU being measured, $X$ is the input matrix, $Y$ is the output matrix and $j=1, \ldots, n$ stands for number of DMUs.

On the other hand, the output-oriented BCC model is formulated as below,

$$
\begin{array}{ll}
\min & \eta_{B} \\
\text { subject to } & \eta_{B} x_{o}-X \lambda \geq 0 \\
& Y \lambda-y_{o} \geq 0 \\
& \sum_{j=1}^{n} \lambda_{j}=1 \\
& \lambda \geq 0,
\end{array}
$$

with $\eta_{B}$ being the reverse of efficiency score of $B^{\text {th }}$ DMU.

Table 7 Summary of DEA analysis conducted

\begin{tabular}{lccc}
\hline Model & Inputs & Outputs & DEA analysis \\
\hline Model 1 & Researchers & Publications & BCC output-oriented \\
& Grants & Technology outputs & \\
& & Awards \\
& & Human Resources & \\
Godel 2 & Grants & Publications & BCC input oriented \\
& & Technology outputs & \\
& & Awards & \\
& & Human resources & BCC output oriented \\
Model 3 & Researchers & Publications & \\
& Grants & & \\
\hline
\end{tabular}

A summary of how the analysis was conducted is presented in Table 7. Model 1 is executed in order to evaluate the overall efficiency of all 152 researches based on the output production. This model operates in two ways. Either the model is executed using the whole set consisting of 152 DMUs, or the model is executed with respect to each 
discipline, which means it is run for a total of 4 times, one for each discipline. Model 2 focuses on using the DEA analysis to find the potential improvement of grants with regards to the current value of output. In contrast to Model 2, Model 3 examines the potential improvement of the publications score by fully utilising both capital and labour resources.

\section{Results and discussions}

\subsection{Model 1}

The purpose of the Model 1 analysis was to measure the efficiency of researches funded by the same type of grants by using DEA. The DMU being measured, i.e., the sponsored research projects, was classified with respect to relevant discipline, years sponsored and the number of collaborations. A total number of two inputs and four outputs were used in the analysis with the BCC output-oriented DEA model.

Table 8 Results of whole and independent DMU analysis

\begin{tabular}{lcccc}
\hline Discipline & $\begin{array}{c}\text { Number of efficient DMU } \\
\text { (whole) }\end{array}$ & $\%$ & $\begin{array}{c}\text { Number of efficient DMU } \\
\text { (within discipline) }\end{array}$ & $\%$ \\
\hline Medicines & 3 & 1.97 & $15(34)$ & 44.12 \\
Sciences & 4 & 2.63 & $14(58)$ & 24.14 \\
Engineering & 9 & 5.92 & $9(48)$ & 18.75 \\
Others & 1 & 0.66 & $6(12)$ & 50 \\
\hline
\end{tabular}

Figure 3 Ratio of efficient DMUs

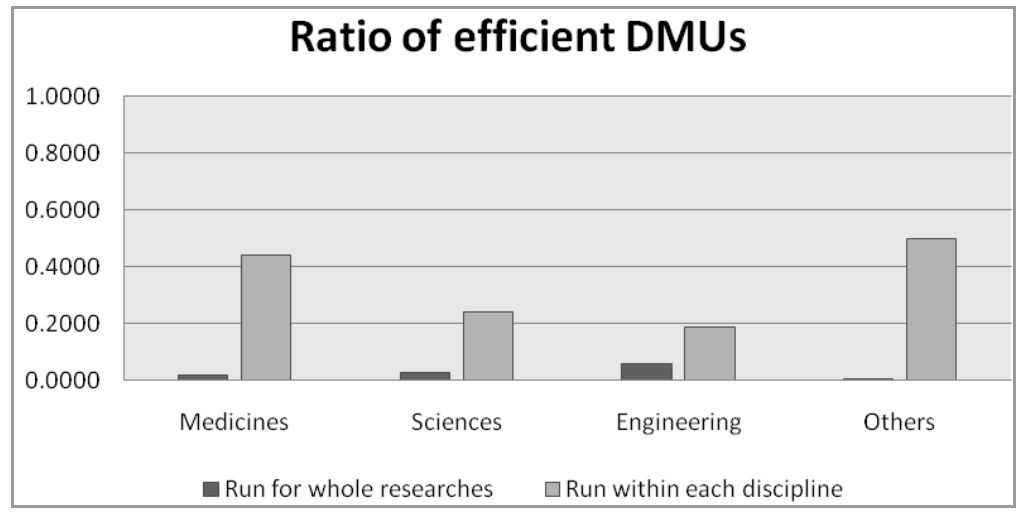

The Model 1 analysis aims to evaluate the sponsored research in two ways. The first objective is to evaluate the overall efficiency of the sponsored research and the second objective is to examine the three different environmental effects on the efficiency scores. Table 8 summarises the percentage of the efficient DMU in both analyses according to discipline and Figure 3 visualises the same results. From Table 8 and Figure 3 it can be seen that Engineering has the largest number of efficient DMUs when analysed against all the factors while other disciplines possessed the least efficient units despite having the highest percentage of the efficient units when tested with a discipline as a factor. The 
initial result indicates that the number of efficient DMUs for Engineering in both types of analyses remaine at nine DMUs. This result is in contrast with that of three other disciplines whereby the number of efficient units increases dramatically when the analysis is conducted with the only discipline as a factor.

Figure 4 DMU's efficiency score distribution based on range

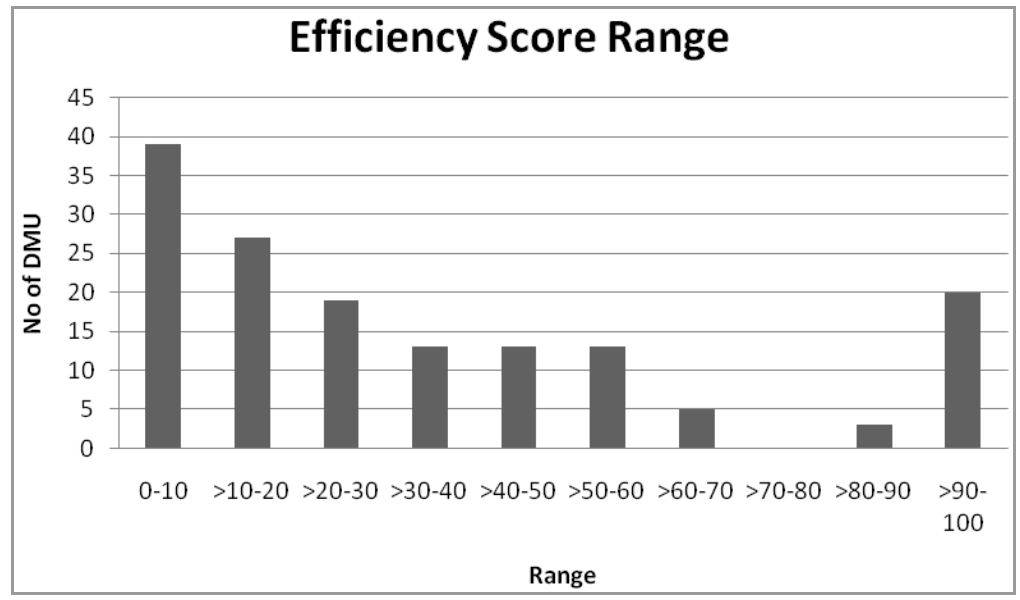

Figure 5 Efficiency score distribution based on discipline

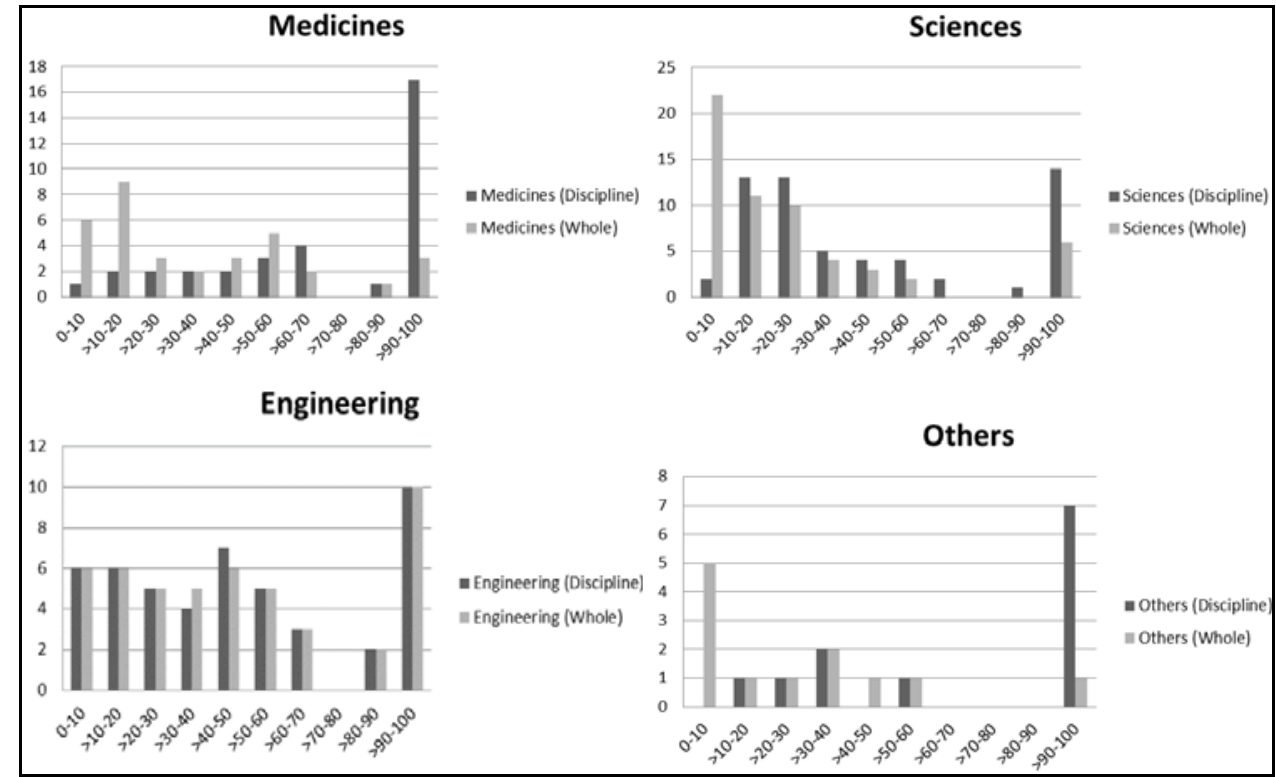

Figure 4 illustrates the distribution of DMU's efficiency score based on the score range. In Figure 4, the first range, 0-10, has the highest count of DMU which is 39 in total. There are 20 DMU units in the score range of more than 90 to 100 with 17 of them having the efficiency score of 100. No DMU is recorded to have the score of between 70 to 80 . Figure 5 illustrates the comparison of the range distribution when the DMU is run 
within the discipline and as a whole. It can be observed that apart from engineering, three other disciplines demonstrate a dramatic change in the efficiency score when the two analyses were conducted. The number of efficient DMUs suddenly increases in the analysis when only the DMU from the same discipline is considered.

Conclusively, the findings in this initial analysis for all disciplines reveal that too many DMU are classified as inefficient. 41 DMU score more than 50 in the efficiency score in the overall analysis. The results of the analysis according to discipline reveals that more research projects are able to perform well when the performance is evaluated in its discipline only. Cumulatively, 74 DMUs manage to obtain at least $50 \%$ of the efficiency score. This finding showed the existence of non-homogeneity in the research being evaluated on discipline.

Table 9 Results of discipline comparison

\begin{tabular}{lcccc}
\hline Discipline & $N$ & Median & Average efficiency & Average rank \\
\hline Medicines & 34 & 27.06 & 34.57 & 75.09 \\
Sciences & 58 & 17.11 & 29.36 & 88.97 \\
Engineering & 48 & 46.44 & 49.8 & 56.74 \\
Others & 12 & 34.28 & 33.64 & 81.08 \\
\hline
\end{tabular}

Notes: $\mathrm{H}$ statistics $=23.9, \mathrm{P}$ value $=0.003$.

Table 10 Results of years sponsored comparison

\begin{tabular}{lcccc}
\hline Years & $N$ & Median & Average efficiency & Average rank \\
\hline 1 years & 4 & 57.9 & 45.51 & 55 \\
2 years & 28 & 20.74 & 28.82 & 91.25 \\
3 years & 77 & 28.02 & 38.88 & 72.64 \\
4 years & 39 & 33.92 & 37.48 & 75.97 \\
$>$ 4 years & 4 & 44.1 & 55.84 & 43.5 \\
\hline
\end{tabular}

Notes: $\mathrm{H}$ statistics $=6.72, \mathrm{P}$ value $=0.243$.

Table 11 Results of collaborations comparison

\begin{tabular}{llccc}
\hline Collaboration & $N$ & Median & Average efficiency & Average rank \\
\hline 1 Collaboration & 74 & 37 & 43 & 67.91 \\
2 Collaborations & 50 & 25.24 & 33.07 & 80.84 \\
3 Collaborations & 17 & 25.9 & 34.44 & 77.88 \\
$>$ 3 Collaborations & 11 & 13.99 & 22.43 & 101.27 \\
\hline
\end{tabular}

Notes: $\mathrm{H}$ statistics $=6.21, \mathrm{P}$ value $=0.102$.

To support the findings and to further analyse the difference of performance in each discipline, the non-parametric statistical test named the Kruskal-Wallis test was used. The test was run to compare the performance of each discipline and then extended to investigate further the effect of 'years sponsored' and 'number of collaborations' with the null hypothesis being defined such that the mean efficiencies of all groups were the same. From Table 9, we could see that the p value is equal to 0.003 at $95 \%$ confidence interval which suggests that we could reject the null hypothesis for the first case and concludes that at least, the mean of one discipline is different from the others. Tables 10 and 11 
conclude that the analysis for 'years sponsored' and 'number of collaborations' in the result of both cases accepts the null hypothesis and there is no difference in mean efficiencies for both factors.

Figure 6 Average efficiency and rank of DMUs in each discipline

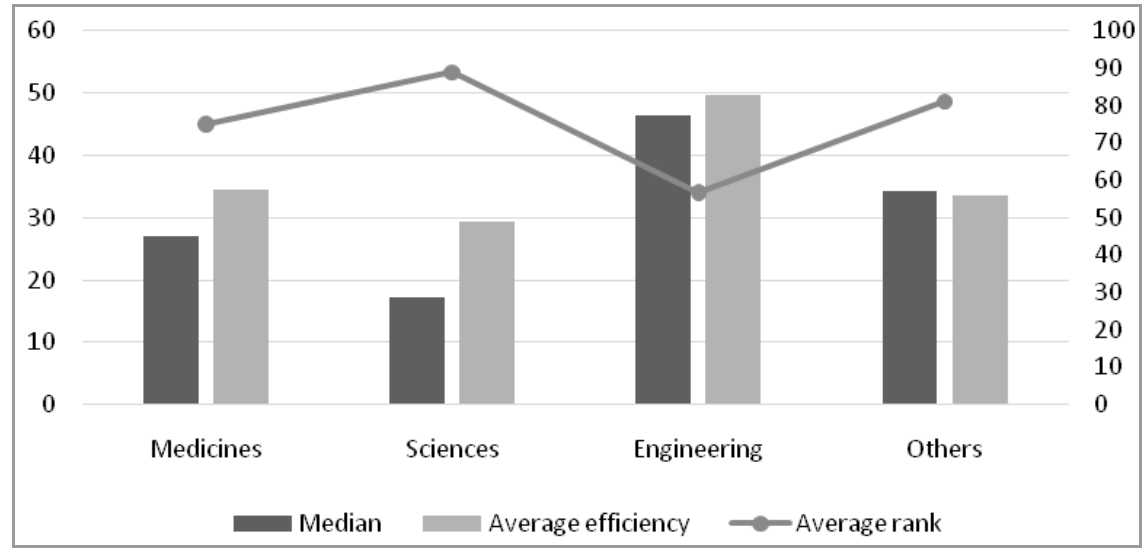

Figure 6 visualises the summary of the average efficiency and rank of DMUs in each discipline. It is apparent that Engineering has the highest average efficiency and the lowest average rank. This result makes the engineering discipline the most efficient. For other disciplines, one of the reasons why it has the highest average rank is because it has the least number of research projects under its category. Research in sciences tends to have the highest average rank and the lowest average efficiency scores which put them at the bottom of the four disciplines. Discussing the results of the statistical analysis, the performance of at least one discipline differed from the others which suggest that the research projects performed differently according to discipline.

Figure 7 Average efficiency and rank of DMUs according to years completed

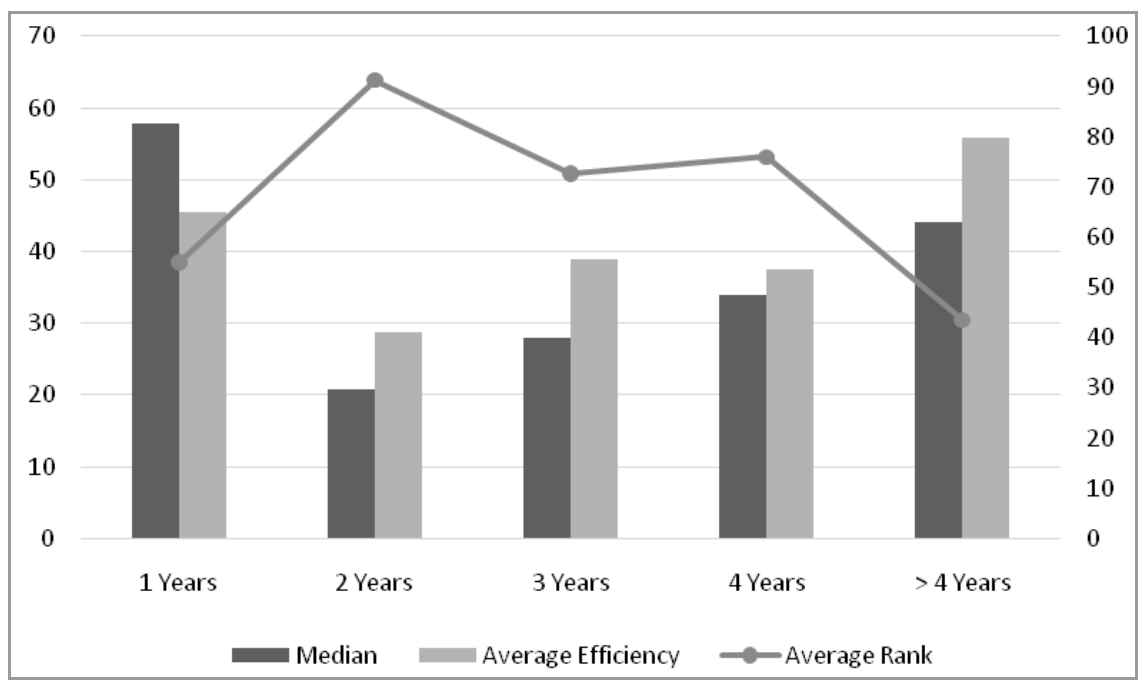


Figure 7 visualises the results of the analysis according to the years sponsored. The average efficiency of the research sponsored within the time constraint of 12 months and more than 48 months ranks in the top two among the five categories. This result is because both categories only have four DMUs to be evaluated. Despite having the highest number of DMU in its category, research projects sponsored for the duration up to 36 months have the third highest average efficiency score.

Figure 8 Average efficiency and rank of DMUs according to number of collaborations

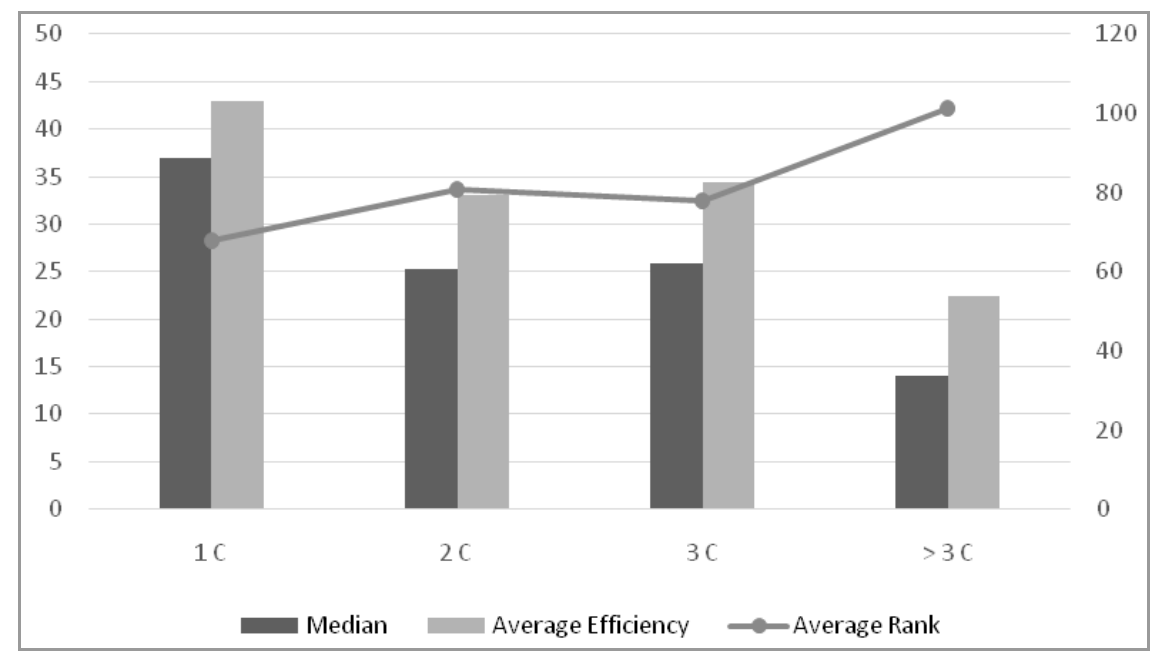

Figure 8 illustrates the summary of analysis for research projects on the number of inter-department collaborations. A total of 74 research projects are conducted under one department and this category has the highest average efficiency as well as the lowest average rank compared to three other categories. In contrast to the result from the tests with 'years sponsored', the collaboration that involves more than three departments, having only 11 research projects under its category, scores lowest in average efficiency and highest in average rank.

\subsection{Model 2}

The analysis of Model 2 aimed to examine a potential improvement of the sponsored research inputs. Since the number of researchers represents the speciality required to complete the research, only the potential improvement of the capital input of the research is considered. The analysis was conducted using the BCC input-oriented DEA model with grants being the single input. This part of the analysis was done to answer the question of possible input reduction with the current output production. For future reference, sponsor and researchers can apply this method to find out the possible amount of grant allocation with a pre-determined value of output, i.e., production.

The result of this analysis, as presented in Table 12 suggests that all four disciplines have the possibility of reducing the amount of grant with the current input. The total grant reduction is rather high because the output produced by most of the research projects is low compared to the number of grants allocated. However, this is just estimation for future reference. The need for a specific amount of money for research might vary 
according to the requirement of each study. This analysis only provides the foundation of possible improvement in cost reduction.

Table 12 Descriptive statistics for potential improvement for research grants

\begin{tabular}{lccccc}
\hline Discipline & Mean & Standard deviation & Minimum & Maximum & \% total reduction \\
\hline Medicines & 148,077 & 263,348 & 64,410 & $1,500,000$ & 58.21 \\
Sciences & 272,259 & $1,473,597$ & 64,410 & $11,299,914$ & 50.78 \\
Engineering & 103,779 & 45,182 & 64,000 & 242,000 & 50.14 \\
Others & 78,311 & 15,760 & 64,410 & 105,089 & 46.54 \\
\hline
\end{tabular}

\subsection{Model 3}

This part of the analysis would provide the potential improvement for the publications without altering the current input. The analysis would only examine the possible potential improvement for publications since only 9 out of 152 DMUs did not produce any publications. Furthermore, as suggested by Martin (2003), almost 60\% of studies regarding research included publications as an area of interest. Therefore, this phase will only focus on that particular output.

Table 13 Descriptive statistics for potential improvement for publications

\begin{tabular}{lccccc}
\hline Discipline & Mean & Standard deviation & Minimum & Maximum & \% total improvement \\
\hline Medicines & 37.4742 & 9.8941 & 2.87 & 53.49 & 413.62 \\
Sciences & 41.0559 & 27.2024 & 16.85 & 219.14 & 516.58 \\
Engineering & 35.2112 & 19.2372 & 1.79 & 39.64 & 303.07 \\
Others & 28.7749 & 10.9355 & 12.36 & 40.65 & 712.39 \\
\hline
\end{tabular}

Table 13 summarises the potential improvement for publications for each discipline. The results suggest that all four disciplines should increase the number of publications such that no research project produces zero value for this particular output. Engineering requires the least improvement, which supports our previous findings that this discipline has the highest average efficiency. The outcome of this analysis is to provide a mathematical method of determining an output value in proportion to the resources allocated by the sponsor.

\section{Conclusions}

A new way of evaluating the performance of grant awarded research projects using MACBETH and DEA has thus been presented. The application of MACBETH managed to overcome the problem of low discrimination power of DEA by reducing the number of output variables. This step was required to perform the DEA analysis and avoid having too many zero output values for the analysis.

The results of the statistical analysis showed that the performance of the DMU differed among the research discipline and therefore suggests a heterogeneity characteristic of the DMU in that particular environmental variable. The statistical test, 
however, did not support the difference in the mean efficiencies among the research for the 'years sponsored' and 'number of inter-department collaborations'.

From the further analysis, it can be concluded that on average, sponsored research perform poorly. This is based on the average potential improvement suggested to achieve the efficient score. Hence this analysis provides a base for potential sponsors in allocating the resources and for future researchers in attaining the target in accordance with their allocated input.

Another significant finding from this study is the existence of non-homogeneity characteristics in the sponsored research disciplines that might affect the overall analysis. This aspect requires improvement involving the non-homogeneous DEA that would cater to the need of evaluating the performance of sponsored researches by considering its nonhomogeneous characteristics. In comparing or evaluating research from different disciplines, particularly the arts or sciences, care should be taken on the non-homogeneity issues.

\section{Acknowledgements}

The authors would like to thank Professor Dato' Dr Muhammad Jantan, Deputy Vice-Chancellor (research and innovation) of University Sains Malaysia, Penang, Malaysia for allowing us access to the data used in this paper.

\section{References}

Abramo, G., Cicero, T. and D'Angelo, C.A. (2011) 'A field-standardized application of DEA to national-scale research assessment of universities', Journal of Informetrics, Vol. 5, No. 4, pp.618-628.

Adler, N., Friedman, L. and Sinuany-Stern, Z. (2002) 'Review of ranking methods in the data envelopment analysis context', European Journal of Operational Research, Vol. 140, No. 2, pp.249-265.

Afzal, M.N.I. and Lawrey, R. (2014) 'Measuring the importance and efficiency of research and development expenditures in the transformation of knowledge-based economies: a case study of the ASEAN region', International Journal of Asia Pacific Studies, Vol. 10, No. 1, pp.33-47.

Agasisti, T., Dal Bianco, A., Landoni, P., Sala, A. and Salerno, M. (2011) 'Evaluating the efficiency of research in academic departments: An empirical analysis in an Italian region', Higher Education Quarterly, Vol. 65, No. 3, pp.267-289.

Bana e Costa, C.A. and Oliveira, M.D. (2012) 'A multicriteria decision analysis model for faculty evaluation', Omega, Vol. 40, No. 4, pp.424-436.

Bana e Costa, C.A. and Vansnick, J-C. (1994) 'MACBETH - An interactive path towards the construction of cardinal value functions', International Transactions in Operational Research, Vol. 1, No. 4, pp.489-500.

Banker, R.D., Charnes, A. and Cooper, W.W. (1984) 'Some models for estimating technical and scale inefficiencies in data envelopment analysis', Management Science, Vol. 30, No. 9, pp.1078-1092.

Charnes, A., Cooper, W.W. and Rhodes, E. (1978) 'Measuring the efficiency of decision making units', European Journal of Operational Research, Vol. 2, No. 6, pp.429-444. 
Chen, C-T., Chien, C-F., Lin, M-H. and Wang, J-T. (2004) 'Using DEA to evaluate R\&D performance of the computers and peripherals firms in Taiwan', International Journal of Business, Vol. 9, No. 4, pp.347-360.

Cooper, W.W., Seiford, L.M. and Tone, K. (2000) Data Envelopment Analysis. A Comprehensive Text with Models, Applications, Reference and DEA-Solver Software, Springer, New York.

Cullman, A., Schmidt-Ehmcke, J. and Zloczysti, P. (2009) Innovation, R\&D Efficiency and the Impact of the Regulatory Environment: A Two Stage Semi Parametric DEA Approach, Discussion Paper, German Institute for Economic Research, Berlin.

Dana, L.P. (1987) 'Industrial development efforts in Malaysia and Singapore,' Journal of Small Business Management, Vol. XXV, No. 3, pp.74-76.

Dana, L.P. (2007) Asian Models of Entrepreneurship: From the Indian Union and the Kingdom of Nepal to the Japanese Archipelago: Context, Policy and Practice, World Scientific, Singapore.

Feng, Y.J. and Lu, H.I.K. (2004) 'An AHP/DEA method for measurement of the efficiency of R\&D management activities in universities', International Transactions in Operational Research, Vol. 11, No. 2, pp.181-191.

Hao, M. and Yanhui, W. (2014) 'R\&D growth and efficiency of scientific research development institutes in China', Journal of Chemical and Pharmaceutical Research, Vol. 6, No. 4, pp.182-187.

Ibanez, A., Larranaga, P. and Bielza, C. (2013) 'Cluster methods for assessing research performance: exploring Spanish computer science', Scientometrics, Vol. 97, No. 3, pp.571-600.

Kocher, M.G., Luptacik, M. and Sutter, M. (2006) 'Measuring productivity of research in economics. A cross-country study using DEA', Socio-Economic Planning Sciences, Vol. 40, No. 4, pp.314-332.

Korhonen, P., Tainio, R. and Wallenius, J. (2001) 'Value efficiency analysis of academic research', European Journal of Operational Research, Vol. 130, No. 1, pp.121-132.

Lee, H., Park, Y. and Choi, H. (2009) 'Comparative evaluation performance of national R\&D programs with heterogenous objectives: a DEA approach', European Journal of Operational Research, Vol. 196, pp.847-855.

Lee, $\mathrm{K}$ and Yoon, B. (2015) 'The idiosyncrasy of research and development efficiency across types of small- and medium-sized enterprises: evidence from Korea', $R \& D$ Management, Vol. 45, No. 3, pp.250-266.

Li, H. and Hu, B. (2014) 'Study on efficiency optimization of R\&D resources allocation in Shanghai', American Journal of Industrial and Business Management, Vol. 4, No. 5, pp.217-222.

Martin, B.R. (1996) 'The use of multiple indicators in the assessment of basic research', Scientometrics, Vol. 36, No. 3, pp.343-362.

Meng, W., Zhang, D., Qi, L. and Liu, W. (2008) 'Two-level DEA approaches in research evaluation', Omega, Vol. 36, pp.950-957.

Rahimah A.A. (1996) 'Paradigm shift: Malaysia's development plans', Akademika, Vol. 49, No. 1, pp.67-82.

Schmidt-Ehmcke, J. and Zloczysti, P. (2009) Research Efficiency in Manufacturing - An Application of DEA at the Industry Level, Discussion Paper, DIE Berlin, Berlin.

Sharma, S. and Thomas, V.J. (2008) 'Inter-country R\&D efficiency analysis: an application of data envelopment analysis', Scientometrics, Vol. 76, No. 3, pp.483-501.

Soares De Mello, J.C.C.B., Lins, M.P.E., Soeares De Mello, M.H.C. and Gomes E.G. (2002) 'Evaluating the performance of calculus classes using operational research tools', European Journal of Engineering Education, Vol. 27, No. 2, pp.209-218.

Zhang, A., Zhang, Y. and Zhao, R. (2003) 'A study of the R\&D efficiency and productivity of Chinese firms', Journal of Comparative Economics, Vol. 31, No. 3, pp.444-464. 